J. Dairy Sci. 92:607-616

doi:10.3168/jds.2008-1271

(c) American Dairy Science Association, 2009.

\title{
Oligofructose overload induces lameness in cattle
}

\author{
A. M. Danscher, ${ }^{* 1}$ J. M. D. Enemark, ${ }^{*}$ E. Telezhenko, $†$ N. Capion, ${ }^{*}$ C. T. Ekstrøm, $\ddagger$ and M. B. Thoefner ${ }^{*}$ \\ *Department of Large Animal Sciences, Faculty of Life Sciences, University of Copenhagen, DK-2630, Denmark \\ †Department of Animal Environment and Health, Swedish University of Agricultural Sciences, 75007 Uppsala, Sweden \\ $\ddagger$ Department of Natural Sciences, Faculty of Life Sciences, University of Copenhagen, DK-1871, Denmark
}

\begin{abstract}
The aim was to describe the clinical orthopedic implications of oligofructose overload. A group of 8 nonpregnant dairy heifers were given an oral dose of oligofructose $(17 \mathrm{~g} / \mathrm{kg}$ of body weight). At predefined times during a period spanning $3 \mathrm{~d}$ before and $9 \mathrm{~d}$ after oligofructose overload, the heifers underwent a clinical examination including locomotion scoring, hoof-testing, and palpation of tarso-crural joints, as well as the collection of blood and ruminal fluid samples. Locomotion sessions were videotaped; subsequently, locomotion was blind-scored. Locomotion scores increased after oligofructose overload and declined toward the end of the study period. The greatest locomotion scores were recorded on d 3 to 5 (60 to $120 \mathrm{~h}$ ) where 12 of 42 (29\%) locomotion scores were 3 and 13 of $42(32 \%)$ were score 2. Positive reactions to hoof-testing were observed from $30 \mathrm{~h}$ after oligofructose overload and reached a maximum on d 7 and 9 where 12 of $28(43 \%)$ reactions were marked positive. Distension of the tarsocrural joints was observed from $24 \mathrm{~h}$ after oligofructose overload, with maximum distension being observed on d 2, in which 44 of 56 (79\%) of observed joints were either moderately or severely distended. The heifers developed classic signs of acute ruminal and systemic acidosis after the oligofructose overload (ruminal $\mathrm{pH}$ $4.3 \pm 0.07$, standard base excess $-10.8 \pm 2.3$ at $18 \mathrm{~h}$ ). With few exceptions, clinical and laboratory variables returned to normal within $9 \mathrm{~d}$ of oligofructose overload. But, good body condition and previous feeding with grass apparently predisposed the heifers to more severe systemic affection. Oligofructose overload in dairy heifers induced ruminal and systemic acidosis, diarrhea, dehydration, and, subsequently, lameness, claw pain, and joint effusion, collectively interpreted as signs of acute laminitis. Oligofructose overload at $17 \mathrm{~g} / \mathrm{kg}$ of
\end{abstract}

Received April 15, 2008

Accepted October 24, 2008.

${ }^{1}$ Corresponding author: amd@life.ku.dk body weight represented a relatively mild laminitis model in cattle, as demonstrated by a reasonably quick recovery from systemic as well as orthopedic signs.

Key words: oligofructose overload, acute ruminal acidosis, lameness, bovine laminitis

\section{INTRODUCTION}

Despite intensive research into laminitis, the etiology, pathogenesis, and triggering factors leading to the disease in both cattle and horses remain unclear (Bailey et al., 2004; Greenough et al., 2007). Clinical signs of laminitis seldom occur until several days after the triggering events, and this fact complicates the investigation of the pathogenesis in clinical cases. A model with which the disease can be reliably induced with minimal side effects is a prerequisite of effective investigation of the early stages of laminitis pathogenesis.

One model mimicking acute laminitis in horses, described by van Eps and Pollitt (2006), involves oral administration of oligofructose. Oligofructose is a carbohydrate produced by partial hydrolysis of inulin-type fructan, one of the fructans found in pasture grasses (Pavis et al., 2001). Thoefner et al. (2004) tested this model in cattle and found that an oral dose of oligofructose resulted in lameness and reaction to hoof-testing in 4 of 6 heifers. Histological examination of the dermoepidermal junction of the claws revealed changes consistent with acute laminitis (Thoefner et al., 2005). The diagnostic criteria of laminitis were defined as lameness and concurrent reaction to hoof-testing (Thoefner et al., 2004). Subsequently, diagnoses were supported by specific changes in lamellar histology (Thoefner et al., 2005). Nevertheless, locomotion evaluation was performed using a nonrecognized scale, and due to the experimental setup, only assessment of histological changes was blinded.

Greater understanding of the relationship between oligofructose overload and bovine laminitis is needed, but to our knowledge, no other studies of this relationship have yet been reported. Therefore, the present study was performed. The aim was to describe the clinical orthopedic implications of the oligofructose model. 


\section{MATERIALS AND METHODS}

\section{Animals}

A group of 8 nonpregnant Danish Holstein heifers or crosses thereof, aged 15 to $28 \mathrm{mo}(22.8 \pm 4.83 \mathrm{mo})$, with a BW of 276 to $443 \mathrm{~kg}(371 \pm 55.3 \mathrm{~kg})$ were used in the trial. All heifers were clinically healthy, with normal locomotion and no history of severe systemic disease or serious claw lesions. In all, 7 of the 8 heifers were purchased from the same herd.

Each heifer had claws trimmed 8 to $10 \mathrm{~d}$ before the trial. During the experiment, the heifers were housed in tie stalls with a concrete floor, bedded with wood shavings 3 to $4 \mathrm{~cm}$ deep. The heifers were fed grass hay ad libitum ( $8 \%$ total water-soluble sugar content) and were allowed to acclimatize to the tie stall and feed for at least $17 \mathrm{~d}$ before the trial. During the preexperimental period, all heifers were trained intensively so that they could be handled, have their front feet lifted and examined, and be led by hand at a walk and trot. Three days before the trial, indwelling jugular catheters were placed in each heifer via the aural vein (Secalon Seldy, 16G, $42 \mathrm{~cm}$, Becton Dickinson, Franklin Lakes, NJ). If the catheters failed, they were replaced or the jugular vein was catheterized (Milacath Extended Use, 14G, 9 cm, Mila International Inc., Erlanger, KY).

\section{Design}

The study was conducted as an experimental intervention study in which each animal served as its own

Table 1. Times of clinical examination (C), collection of blood (B) and ruminal fluid $(\mathrm{R})$ of heifers challenged with oral oligofructose overload at $0 \mathrm{~h}$

\begin{tabular}{lrlll}
\hline & & Clinical & & \\
Period & Hours & examination & Blood & Rumen \\
\hline Control & -72 & C & B & R \\
& -48 & C & B & \\
& -24 & C & B & \\
d 1 & 0 & C & B & R \\
& 6 & C & B & R \\
& 12 & C & B & R \\
d 2 & 18 & C & B & R \\
& 24 & C & B & \\
& 30 & C & B & R \\
d 3 & 36 & C & B & \\
& 42 & C & B & \\
d 4 & 48 & C & B & \\
d 5 & 60 & C & B & R \\
d 6 & 72 & C & B & \\
d 7 & 84 & C & B & \\
d 9 & 96 & C & B & \\
\hline
\end{tabular}

control. The experiment included a 3 -d control period before oligofructose overload $(0 \mathrm{~h})$ and $9 \mathrm{~d}$ of surveillance afterwards. Clinical examination and sampling were performed during the entire experimental period (Table 1). All animals received the same experimental treatment. For logistical reasons, the heifers were divided into 2 groups of 4 , and the experiment was conducted in 2 blocks.

In the graphical presentation of the results (Figures $1,2,3$, and 4), all observations before oligofructose overload were pooled in the control column. The observations after overload are presented by 1 column per $24 \mathrm{~h}$.

\section{Experimental Treatment}

At time $=0 \mathrm{~h}$, all heifers were challenged with oligofructose (Beneo P95, Orafti Active Food Ingredients, Tienen, Belgium) dissolved in warm tap water at a dose of $17 \mathrm{~g} / \mathrm{kg}$ of BW in $2 \mathrm{~L} / 100 \mathrm{~kg}$ of BW water. The solution was given as a ruminal drench. Five percent of the main dose was given twice daily for $3 \mathrm{~d}$ before the main overload, as described by Thoefner et al. (2004).

\section{Orthopedic Examination}

At 21 time points (Table 1) the heifers underwent an orthopedic examination including the following elements.

Locomotion Assessment. All heifers were led by hand outside on the same hard, slightly uneven ground surface. Locomotion was assessed live on location by nonblinded researchers and scored in accordance with Sprecher et al. (1997); Table 2). In total, 4 researchers participated in the on-location scoring sessions, with 2 researchers being present at each session performing the scoring together. Either Danscher or Thoefner were present at all scoring sessions. In accordance with the original description of the scale, heifers were categorized as lame when receiving a score of $\geq 2$.

All locomotion scoring sessions were videotaped from a lateral viewpoint at a distance of approximately $8 \mathrm{~m}$. The durations of the video sequences were then standardized to approximately $2 \mathrm{~min}$ each. All videotaped locomotion sessions were subsequently blind-scored in random order by 2 independent researchers (Capion and Telezhenko) using the Sprecher et al. (1997) scale. As part of the experimental design, they received no additional training before this study. The purpose of the blind locomotion scoring was to provide unbiased confirmation or disproof of the development of lameness after oligofructose overload.

Hoof-Testing. All 4 front claws were examined. One person lifted the leg while another applied a large standard hoof-tester over the typical site of sole ulcer 
Table 2. Locomotion scoring scale according to Sprecher et al. (1997)

\begin{tabular}{lll}
\hline $\begin{array}{l}\text { Lameness } \\
\text { score }\end{array}$ & $\begin{array}{l}\text { Clinical } \\
\text { description }\end{array}$ & Assessment criteria \\
\hline 1 & Normal & The cow stands and walks with level-back posture. Its gait is normal. \\
2 & Mildly lame & $\begin{array}{c}\text { The cow stands with level-back posture but develops an arched-back posture while walking. } \\
\text { Its gait remains normal. }\end{array}$ \\
3 & Moderately lame & $\begin{array}{c}\text { An arched-back posture is evident both while standing and walking. The cow's gait is best described } \\
\text { as short-striding with } 1 \text { or more limbs. }\end{array}$ \\
& Lame & $\begin{array}{c}\text { An arched-back posture is always evident and gait is best described as } 1 \text { deliberate step at a time. } \\
\text { The cow favors } 1 \text { or more limbs/feet. } \\
\text { The cow additionally demonstrates an inability or extreme reluctance to bear weight on } 1 \\
\text { or more of its limbs/feet. }\end{array}$ \\
\hline
\end{tabular}

(axial sole-bulb junction) and the central part of the dorso-abaxial claw wall. Just enough pressure was applied to visually appreciate the sole horn yield, and the reaction was assessed both as fasciculation in musculus triceps and as attempts to withdraw the leg. Reaction to hoof-testing was subjectively graded as $0=$ no reaction; 1 = slight reaction; or $2=$ marked reaction.

Evaluation of Tarso-Crural Joints. Tarso-crural joints were palpated and subjectively graded as $0=$ no distension; 1 = mild distension; $2=$ moderate distension; or $3=$ severe distension. In addition, subjective assessment of swelling over the coronary band was noted.

Weight-Shifting. It was noted whether the heifers were observed shifting their weight during the period of examination. Weight-shifting was defined as a shifting of weight laterally from 1 leg to another in a monotonous manner, judged not to be caused by flies or other external influences.

\section{General Clinical Examination}

Coinciding with the orthopedic examination, the heifers underwent a general clinical examination including auscultation of heart rate and ruminal contractions per 5 min, measurement of rectal temperature, and visual inspection of respiration frequency. In addition, the following observations were made.

General Demeanor. The general demeanor of the heifers was subjectively assessed and graded as $3=$ normal, undisturbed, and attentive; $2=$ mildly depressed; $1=$ moderately depressed; and $0=$ severely depressed.

Eating Behavior. It was noted whether the heifers were observed eating or ruminating during the period of examination: 1 = observed eating or ruminating and $0=$ not observed eating or ruminating. The amount of available feed eaten was subjectively assessed and noted as $0=$ less than $1 / 3$ of feed eaten; $1=$ more than $2 / 3$ of feed eaten; and $2=$ all feed eaten.

Feces Consistency. The consistency of feces was inspected visually and graded as $1=$ dry, firm; $2=$ normal; $3=$ pasty, soft; $4=$ diarrhea, thin; or $5=$ watery diarrhea.

\section{Samples and Laboratory Tests}

Blood. Samples of blood were taken at selected time points (Table 1) from indwelling catheters. Standard base excess (SBE) was calculated in a stationary blood gas analyzing apparatus (ABL 520, Radiometer, Broenshoej, Denmark) using heparin-stabilized blood within 5 to 10 min of collection. Packed cell volume (PCV) was measured on heparin-stabilized blood using Bets Micro Haematocrit Tubes (Vitrex Medical A/S, Herlev, Denmark, and Micro 20, Hettich Zentrifugen, Bie \& Berntsen A/S, Roedovre, Denmark).

Ruminal Fluid. Samples of ruminal fluid were collected at selected time points (Table 1), and $\mathrm{pH}$ was measured immediately after collection (Cardy Twin $\mathrm{pH}$ Meter, Spectrum Technologies Inc., Plainfield, IL). A 2-point calibration ( $\mathrm{pH} 4$ and 7) was performed before the measurements. Ruminal fluid was obtained via ruminal intubation (Select Collector, special calf edition, Pharmalett, Kolding, Denmark). The first 1 to $2 \mathrm{~L}$ of collected ruminal fluid was discarded to avoid contamination with saliva and tap water. The tube was rinsed between collections.

\section{Additional Treatment}

Supportive therapy was given as Ringer's acetate (Fresenius Kabi, Uppsala, Sweden; $15 \mathrm{~mL} / \mathrm{kg}$ of BW) and sodium bicarbonate $(84 \mathrm{~g} / \mathrm{L} ; 1.5 \mathrm{~mL} / \mathrm{kg}$ of BW) at 18 and $24 \mathrm{~h}$ after oligofructose overload and as calcium borogluconate (14 mg of $\mathrm{Ca} / \mathrm{mL} ; 1.4 \mathrm{~mL} / \mathrm{kg}$ of BW) at 
$18 \mathrm{~h}$. After problems with the indwelling catheters, this schedule had to be abandoned for 2 heifers.

\section{Ethical Considerations}

The experiment was planned and performed in a manner aiming to prevent any unnecessary pain and discomfort in the animals. The experiment was ethically approved by the Danish Animal Experiments Inspectorate (file no. 2006/561-1132) before performance.

\section{Statistical Analysis}

Agreement. Interobserver agreement between the live, on-location locomotion scoring and the blind video scoring was evaluated by calculating weighted $\kappa$ using squared weights (Agresti, 2002). One $\kappa$ value was calculated for each of the blind video scorings.

Marginal Effect. As a preliminary result, the marginal effect between time and locomotion score, hoof-testing, and joint distension was examined using a proportional odds model (Agresti, 2002). The proportional odds model is an extension of the logistic regression model that allows for more than 2 response categories. The proportional odds model assumes that each response can be categorized into 1 of $J$ different groups. The outcome of the ith experiment can be summarized in a vector

$$
\mathrm{Y}_{\mathrm{i}}=\left(\mathrm{Y}_{\mathrm{i} 1}, \mathrm{Y}_{\mathrm{i} 2}, \ldots, \mathrm{Y}_{\mathrm{iJ}}\right)
$$

where exactly 1 of the coordinates is 1 and the others are $0 ; \mathrm{Y}_{\mathrm{i}}$ will be assumed to follow a multinomial distribution

$$
\mathrm{Y}_{\mathrm{i}}=\mathrm{m}\left[1,\left(\mathrm{P}_{\mathrm{i} 1}, \mathrm{P}_{\mathrm{i} 2}, \ldots, \mathrm{P}_{\mathrm{iJ}}\right)\right]
$$

where we consider the cumulative probabilities

$$
Z_{i j}=P\left(Y_{i} \leq j\right) ; j=1, \ldots, J .
$$

As with logistic regression, we model the logit transform

$$
\mathrm{X}_{\mathrm{ij}}=\log \left[\mathrm{Z}_{\mathrm{ij}} /\left(1-\mathrm{Z}_{\mathrm{ij}}\right)\right]=\alpha(\text { time })+\beta(\text { animal })
$$

where $\alpha$ (time) and $\beta$ (animal) are the parameters corresponding to the effects at a given time or animal. Thus, the model resembles a 2-way ANOVA, although the response variable is not Gaussian, but categorical.

Locomotion score, hoof-testing, and joint distension were modeled as a function of time and animal. By examining the relationship between the orthopedic

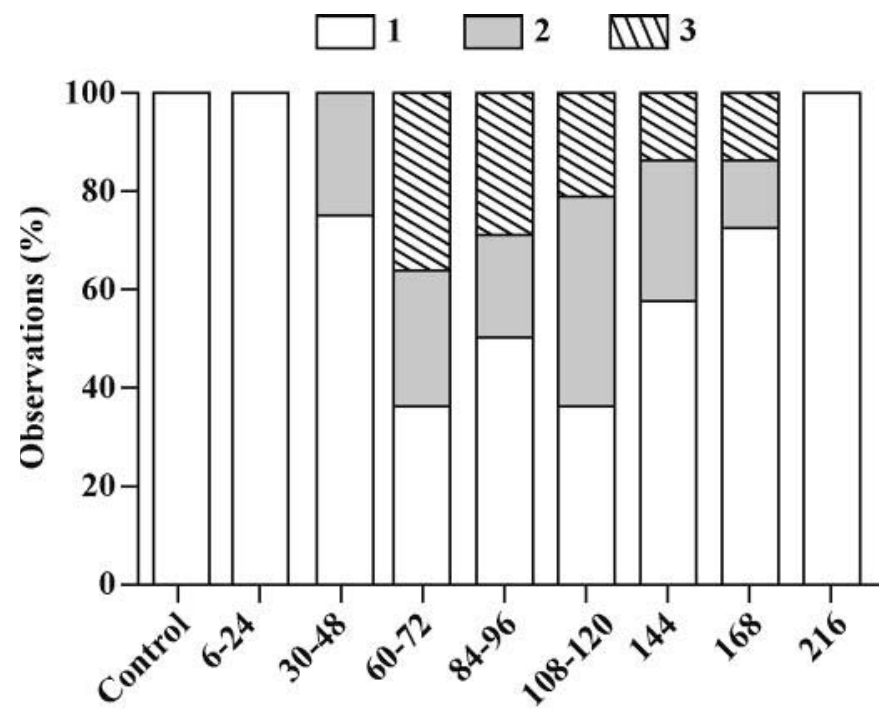

Time (h)

Figure 1. Live locomotion assessment using the Sprecher scale (1 to 5). The heifers were assessed before (control) and after oligofructose overload $(0 \mathrm{~h})$.

variables and time, it was possible to determine if, and when, the locomotion scores differed significantly from those obtained in the control period. The variable "animal" was entered into the model to handle excess variation between animals.

Effect of Weight Group. Differences in ruminal contractions and $\mathrm{pH}$, heart rate, $\mathrm{SBE}$, and $\mathrm{PCV}$ between weight groups were analyzed by a repeated measurements model [PROC MIXED, with time as repeated and type $=\operatorname{sp}($ gau $)$ (time) in SAS 9.1]. Time, group, and the interaction were included as explanatory variables, and heifer and block as random variables. Square root transformation of heart rate and log transformation of PCV was performed before analysis.

\section{RESULTS}

\section{Orthopedic Examination}

Locomotion Assessment. Live locomotion scores observed changed over the course of experiment (Figure 1 ). All heifers were graded as nonlame (grade 1) in the control period ( -72 to $0 \mathrm{~h}$ ) and on d 1 after oligofructose overload ( 6 to $24 \mathrm{~h}$ ). Over the following days, the heifers developed signs of lameness as expressed by an increase in locomotion scores. Maximum scores were recorded on d 3 to 5 (60 to $120 \mathrm{~h}$ ), in which 12 of 42 (29\%) locomotion scores were 3 and 13 of $42(32 \%)$ were score 2. A marked improvement of locomotion was observed during d 6 to 9 of the experiment, with decreasing locomotion scores (10\% score 3 and $14 \%$ score 


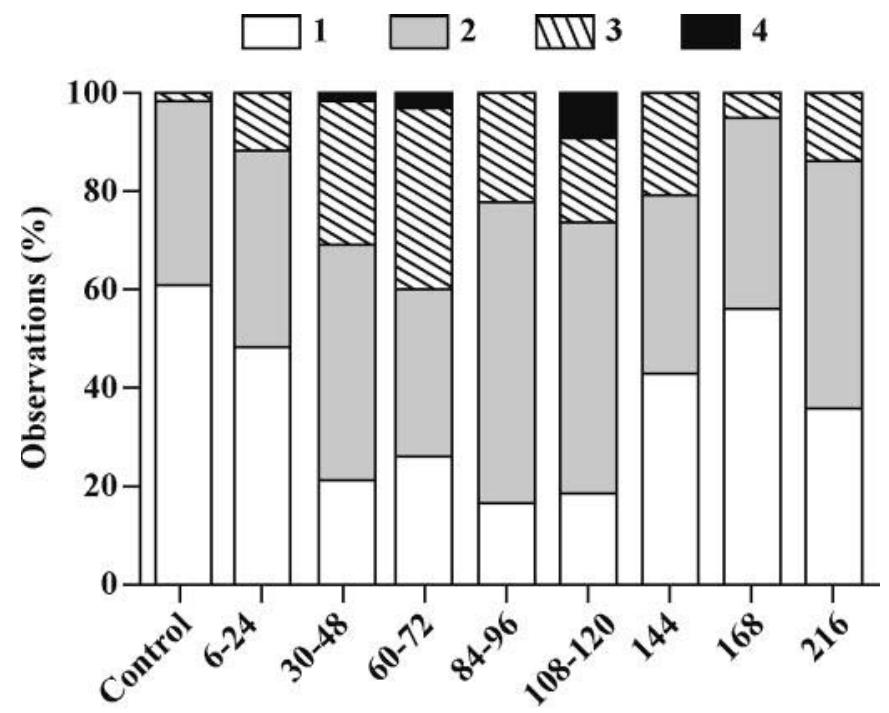

Time (h)

Figure 2. Video locomotion assessment using the Sprecher scale (1 to 5). The heifers were assessed before (control) and after oligofructose overload $(0 \mathrm{~h})$.

$2)$. The locomotion scores were increased $(P<0.05)$ relative to the control period from 30 to $144 \mathrm{~h}$.

The blind video locomotion assessment also revealed a pattern of increasing and subsequent decreasing locomotion scores (Figure 2), but the pattern was less clear. Locomotion scores peaked on d 2 to 5 (30 to $120 \mathrm{~h}$ ), in which 5 of $174(3 \%)$ locomotion scores were 4,74 of 174 $(27 \%)$ were 3 , and 86 of $174(49 \%)$ were score 2 . The video scores were increased $(P<0.05)$ relative to the control period from 30 to $60 \mathrm{~h}, 96$ to $120 \mathrm{~h}$, and from 18 to $144 \mathrm{~h}$, as observed by the 2 blind researchers, respectively.

The agreement between the locomotion scores obtained live and the 2 video scorings expressed by weighted $\kappa$ value was 0.40 and 0.30 .

Hoof-Testing. Few heifers (4\%, 4 out of 112 examined claws) reacted to hoof-testing in the control period and on d 1 after oligofructose overload $(-72$ to $24 \mathrm{~h}$; Figure 3 ). From $30 \mathrm{~h}$ onwards, an increasing proportion of the heifers reacted positively, resulting in a maximum of $43 \%$ (12 of 28 ) marked positive reactions (score 2) on d 7 and 9 (168 and $216 \mathrm{~h}$ ). The hoof-testing scores were increased $(P<0.05)$ relative to the control period from 24 to $216 \mathrm{~h}$.

Evaluation of Tarso-Crural Joints. In the control period, $98 \%$ of observed tarso-crural joints were not distended (85\%, 46 of 54 observed joints) or mildly distended (13\%, 7 of 54; Figure 4). At $24 \mathrm{~h}$ after oligofructose overload, severe distension was observed in 4 of 12 observed joints (33\%), and on d 2 (30 to $48 \mathrm{~h}), 79 \%$

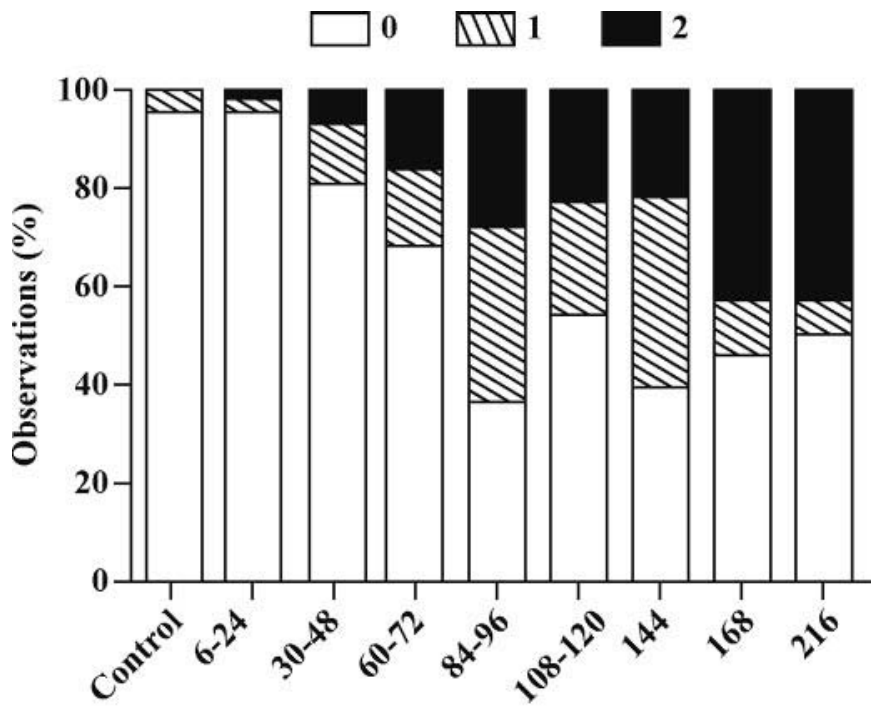

Time (h)

Figure 3. Hoof-testing in heifers before (control) and after oligofructose overload $(0 \mathrm{~h}) .0=$ no reaction; $1=$ slight reaction; $2=$ marked reaction.

(44 of 56) of observed joints were either moderately $(61 \%, 34$ of 56$)$ or severely distended $(18 \%, 10$ of 56$)$. From d 3 onwards, the distension regressed, and on d 9, $79 \%$ (11 of 14 ) of joints were either mildly $(36 \%$, 5 of 14$)$ or not distended $(43 \%, 6$ of 14$)$. The joint distension scores were increased $(P<0.05)$ relative to

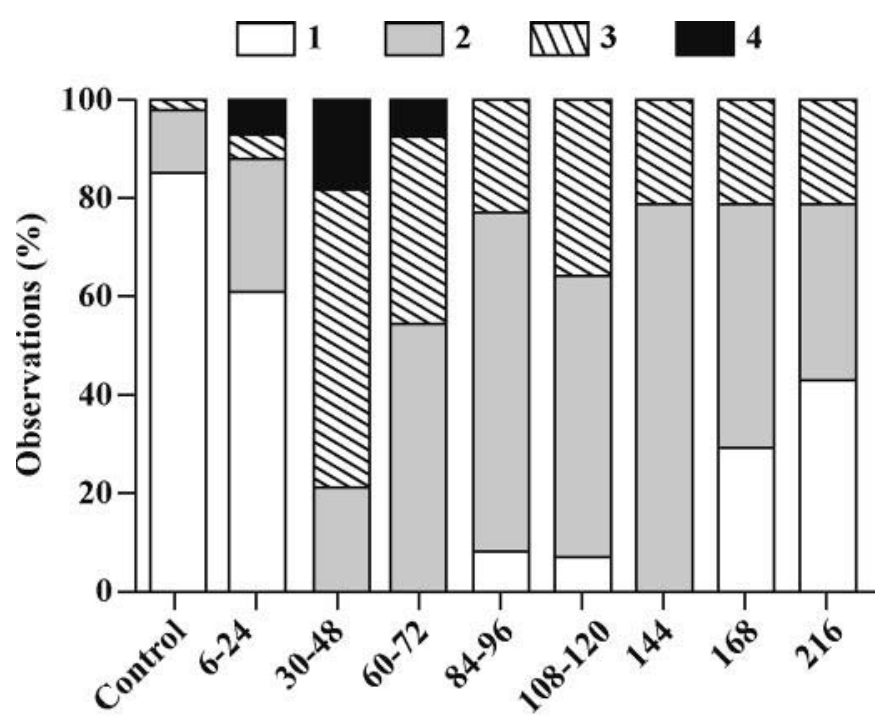

Time (h)

Figure 4. Clinical evaluation of tarso-crural joints in heifers before (control) and after oligofructose overload $(0 \mathrm{~h}) .0=$ no distension; $1=$ mild distension; $2=$ moderate distension; $3=$ severe distension. 


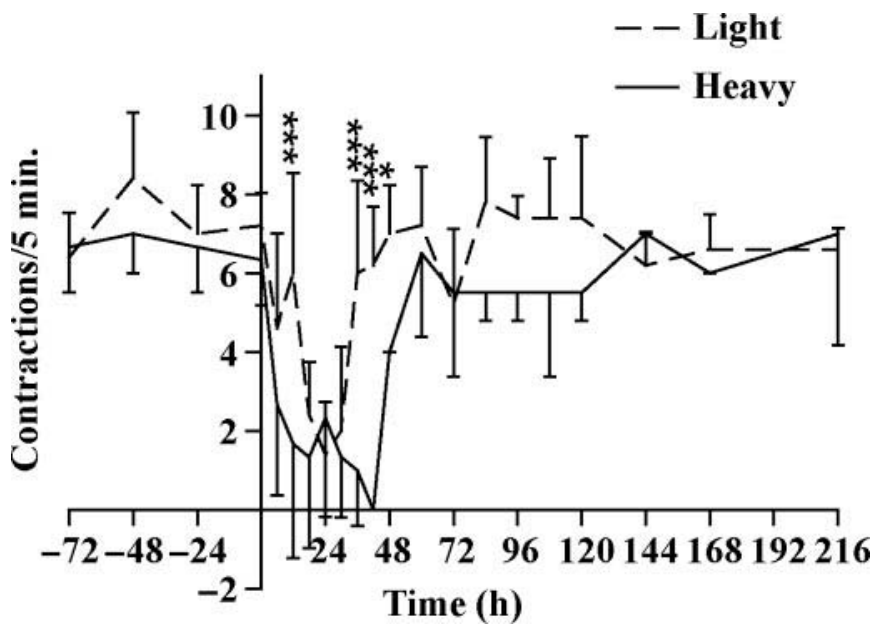

Figure 5. Ruminal contractions (mean \pm SD) of the 3 heaviest heifers $(425 \pm 26.2 \mathrm{~kg})$ and the 5 lighter heifers $(338 \pm 38.1 \mathrm{~kg})$ before and after oligofructose overload $(0 \mathrm{~h})$. One heifer from the heavy group was withdrawn from the study $30 \mathrm{~h}$ after oligofructose overload and contributes only to the results from -72 to $30 \mathrm{~h}$. ${ }^{*} P<0.05$; ${ }^{*} P<$ $0.01 ; * * P<0.001$.

the control period from 24 to $216 \mathrm{~h}$. In addition, an indistinct swelling and hyperemia over the coronary band was observed in several heifers.

Weight-Shifting. Weight-shifting was observed in all but 1 heifer after oligofructose overload. It involved both front and hind limbs. One heifer was observed weight-shifting during every examination from 18 to 144 h. Others shifted weight intermittently and 1 displayed no weight-shifting activity at all. Weight-shifting was first noted at $12 \mathrm{~h}$ after oligofructose overload and was last seen at $144 \mathrm{~h}$. Most incidents of weight-shifting were observed between 12 and $48 \mathrm{~h}$.

\section{General Clinical Examination}

The heifers developed classic signs of acute ruminal and systemic metabolic acidosis after receiving the oligofructose overload (ruminal pH $4.3 \pm 0.07$, SBE -10.8 \pm 2.3 at $18 \mathrm{~h}$ ). All heifers developed anorexia and depression, with the deepest depression being observed at $30 \mathrm{~h}$ after overload. They resumed eating 30 to 60 $\mathrm{h}$ after oligofructose overload, and by $96 \mathrm{~h}$ (4 d), undisturbed general demeanor was observed in all heifers. All heifers developed profuse watery diarrhea starting between 6 and $24 \mathrm{~h}$. During d 2 and afterwards, the diarrhea slowly subsided, and by d 7 , fecal consistency had normalized (data not shown).

Although the heifers displayed a similar pattern of clinical signs, there was a wide variation in how severely they were affected. The 3 heaviest heifers ( 425 $\pm 26.2 \mathrm{~kg}$ of $\mathrm{BW}$ ) tended to be more severely affected by the systemic disease than the 5 lighter ones (338

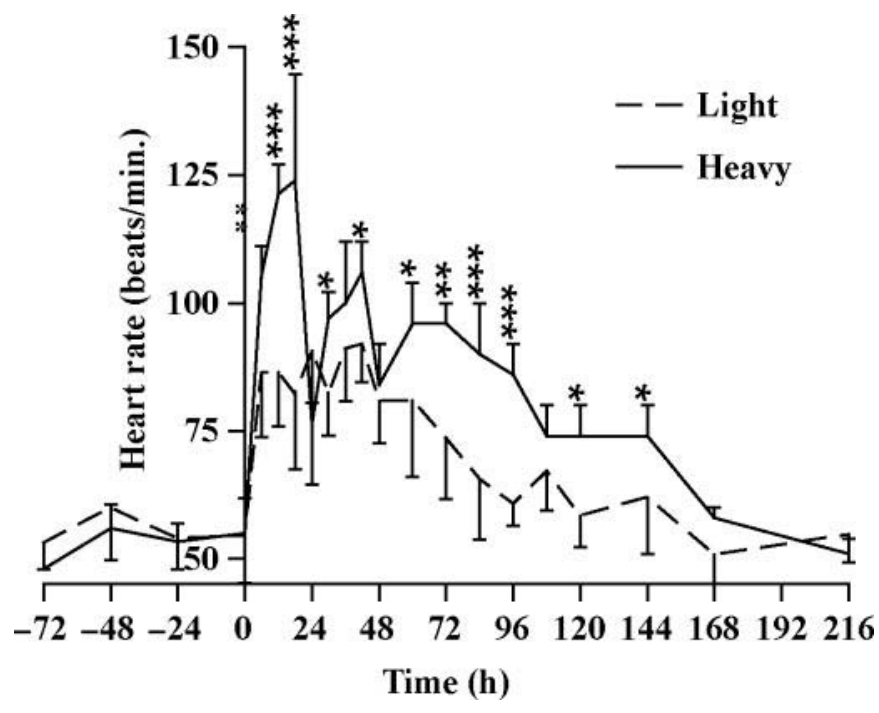

Figure 6. Heart rate (mean and SD) of the 3 heaviest heifers $(425$ $\pm 26.2 \mathrm{~kg})$ and the 5 lighter heifers $(338 \pm 38.1 \mathrm{~kg}$ ) before and after oligofructose overload $(0 \mathrm{~h})$. One heifer from the heavy group was withdrawn from the study $30 \mathrm{~h}$ after oligofructose overload and contributes only to the results from -72 to $30 \mathrm{~h} .{ }^{*} P<0.05$; ${ }^{* *} P<0.01$; $* * * P<0.001$.

$\pm 38.1 \mathrm{~kg}$ of $\mathrm{BW}$ ). The heavy heifers showed a rapid decline in frequency of ruminal contractions and attained greater heart rates (Figures 5 and 6). In the heavy heifers, ruminal fluid $\mathrm{pH}$ stayed low (4 to 4.5) at $30 \mathrm{~h}$, whereas ruminal $\mathrm{pH}$ increased between 18 and $30 \mathrm{~h}$ in the lighter heifers (Figure 7). Initially, SBE declined at the same rate in both groups (Figure 8). In

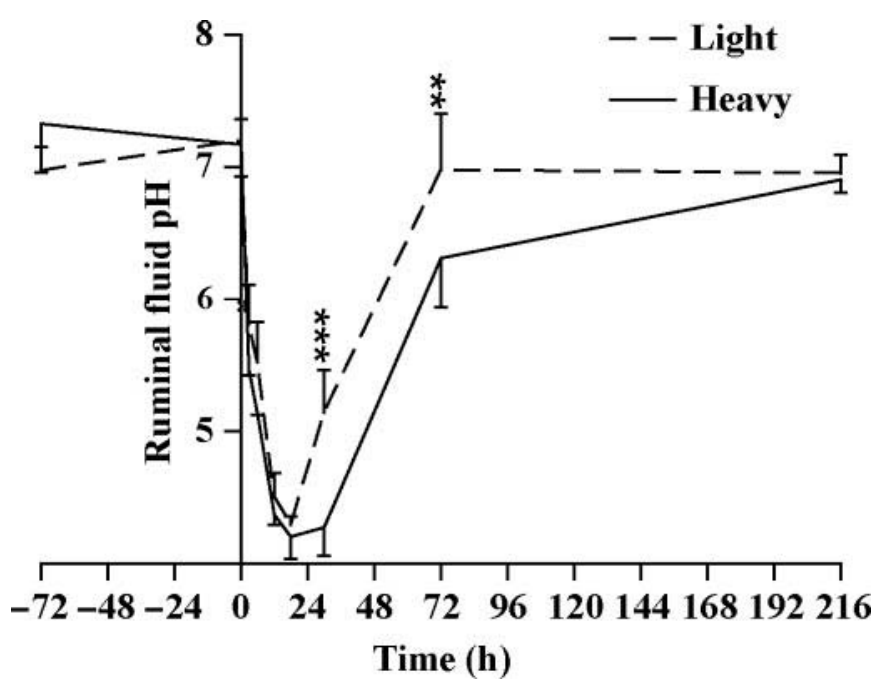

Figure 7. Ruminal fluid pH (mean and SD) of the 3 heaviest heifers $(425 \pm 26.2 \mathrm{~kg})$ and the 5 lighter heifers $(338 \pm 38.1 \mathrm{~kg})$ before and after oligofructose overload $(0 \mathrm{~h})$. One heifer from the heavy group was withdrawn from the study $30 \mathrm{~h}$ after oligofructose overload and contributes only to the results from -72 to $30 \mathrm{~h} .{ }^{*} P<0.05 ;{ }^{* *} P<$ $0.01 ; * * * P<0.001$. 


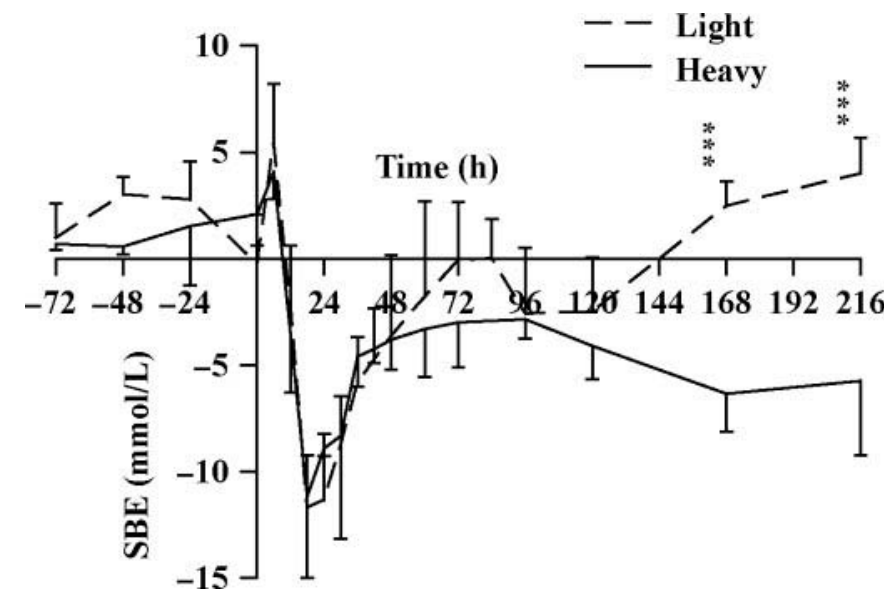

Figure 8. Standard base excess (SBE; mean and SD) of the 3 heaviest heifers $(425 \pm 26.2 \mathrm{~kg})$ and the 5 lighter heifers $(338 \pm 38.1$ $\mathrm{kg}$ ) before and after oligofructose overload $(0 \mathrm{~h})$. One heifer from the heavy group was withdrawn from the study $30 \mathrm{~h}$ after oligofructose overload and contributes only to the results from -72 to $30 \mathrm{~h}$. ${ }^{*} P<$ $0.05 ;{ }^{* *} P<0.01 ;{ }^{* * *} P<0.001$.

the heavy heifers, a second decline in SBE was observed from 72 to $120 \mathrm{~h}$, and SBE stayed below reference values on d 7 and 9, when the lighter heifers had normalized. Packed cell volume increased rapidly after oligofructose overload and reached greater values in the heavy group; a second increase in PCV was observed between 24 and $48 \mathrm{~h}$ (Figure 9).

After the study period, the heifers were turned out on pasture. A week later, no lameness was observable.

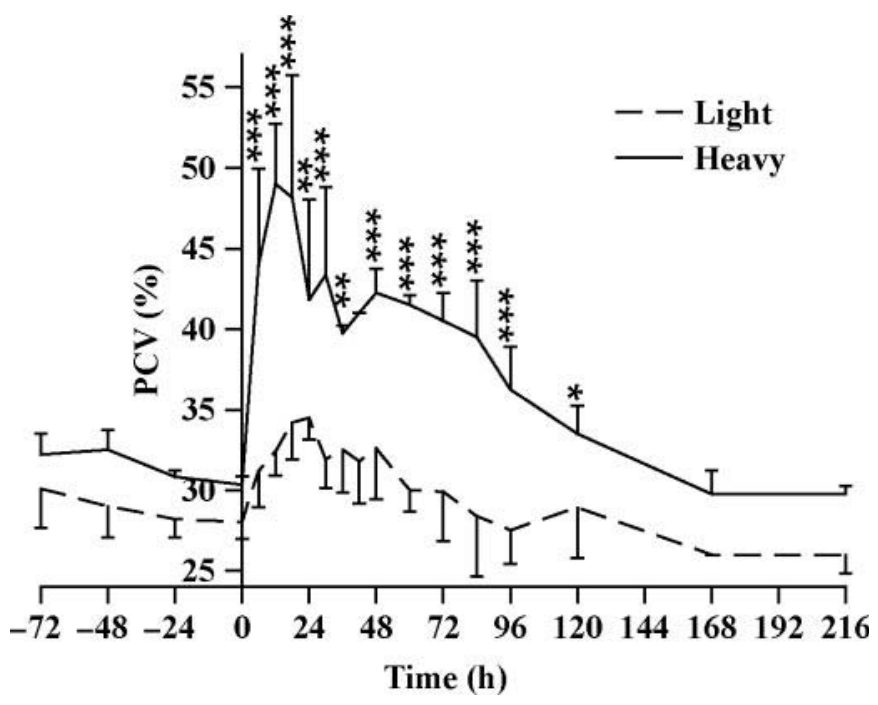

Figure 9. Packed cell volume (PCV; mean and SD) of the 3 heaviest heifers $(425 \pm 26.2 \mathrm{~kg})$ and the 5 lighter heifers $(338 \pm 38.1 \mathrm{~kg})$ before and after oligofructose overload $(0 \mathrm{~h})$. One heifer from the heavy group was withdrawn from the study $30 \mathrm{~h}$ after oligofructose overload and contributes only to the results from -72 to $30 \mathrm{~h}$. ${ }^{*} P<0.05$; ${ }^{* *} P$ $<0.01 ;{ }^{* * *} P<0.001$.
After full restitution, 2 heifers were slaughtered and the rest were sold to a commercial dairy producer. Seventeen months after the trial, 1 heifer had been culled in response to udder problems; the remainder were functioning and producing normally.

Animal Excluded from the Study. One heifer's reaction to the oligofructose overload was markedly more severe than that of the others. The heifer was depressed and anorectic earlier, and more severely, than the other heifers. It had a greater heart rate and developed transient hypothermia and continued ruminal stasis. Its ruminal $\mathrm{pH}$ was very low (4.0) at 18 and $30 \mathrm{~h}$, and it developed a deep and noncompensated, systemic metabolic acidosis and dehydration that responded inadequately to the fluid therapy regimen described in the trial protocol. For welfare reasons, the heifer was withdrawn from the study at $30 \mathrm{~h}$, but despite vigorous therapy and apparent improvement of its clinical condition, it did not survive. Lesions at autopsy suggested failure of the kidneys, liver, and heart as a consequence of previous severe dehydration or toxemia. The data from this heifer do not contribute to the orthopedic results, but they are included in the graphic presentation of the weight groups (Figures 5 to 9).

\section{DISCUSSION}

\section{Orthopedic Examination}

Lameness or Laminitis? The present study confirms that the oligofructose model does induce lameness in dairy heifers, as described by Thoefner et al. (2004). But, can it be concluded that oligofructose induces laminitis?

Bovine laminitis is not a well-defined condition. Literally, laminitis means inflammation of the lamellae of the claw. Nilsson (1963) defines bovine laminitis as "a diffuse, acute, subacute or chronic aseptic pododermatitis usually involving the tissues of several hooves and leading to local and mostly systemic clinical signs." Greenough et al. (2007) has broadened the definition to "a systemic disease with local manifestations in the claw," and Ossent et al. (1997) state that it is characterized by a rapid onset of claw pain and lameness. The present study investigated the acute form of laminitis. The direct involvement of the lamellae was not investigated. Nonetheless, the observed increase in sensitivity to hoof-testing suggests that claw pain was present, and Thoefner et al. (2005) found histological evidence of lamellar pathology after oligofructose overload. On the other hand, claw pain persisted, whereas lameness declined at the end of the experiment. This implies that claw pain may not be the sole source of acute lameness in this model. 
The present study clearly supports the common perception of laminitis as a systemic disease with local manifestations. Still, locomotor system manifestations were observed in the tarso-crural joints as well as in the claws. This observation gives rise to the question of when and how much joint reaction contributed to the observed lameness. The clinical observations suggest that joint pain contributed to the observed lameness primarily in the early period after oligofructose overload, whereas hoof pain may be responsible for late-phase lameness in the present study. Furthermore, weight-shifting was mainly observed early on in the study; consequently, it coincided with joint affection.

Conclusively, oligofructose induced signs of lameness, as well as concurrent systemic signs that were consistent with acute laminitis broadly defined. To what degree pain in the claw, joints, and perhaps other synovial structures contributes to the observed lameness remains to be investigated.

Locomotion Assessment. The main purpose of the video scoring was to determine whether oligofructose overload resulted in lameness at a level that would be appreciated by unbiased observers with no prior knowledge of the animals. We believe the video scoring confirmed that lameness developed after oligofructose overload. Throughout the experiment, the video observers scored more harshly than the live observers. The agreement between live locomotion scoring and video scoring was poor to fair (Ersboel et al., 2004). Other studies have shown that agreement on locomotion scorings varies over a wide range and that inter- and intraobserver agreement improves with the increased experience of the observers (O'Callaghan et al., 2003; Brenninkmeyer et al., 2007; March et al., 2007).

Locomotion scoring remains a subjective evaluation method. Even when assessment criteria are meticulously described, it continues to be vulnerable to the idiosyncrasies of the person assessing and interpreting the animal. But, it remains the best option for in-thefield assessment of locomotion in cattle. A reliable, relatively fast, and economically feasible method of objective locomotion evaluation in cattle and horses is highly desirable and would contribute greatly to future research and welfare assessment.

Thoefner et al. (2004) observed lameness in 4 of 6 heifers $39 \mathrm{~h}$ after oligofructose overload or later. In the present study, individual heifers had gait abnormalities as early as $30 \mathrm{~h}$ after oligofructose overload, but obvious, consistent lameness was only observed from $42 \mathrm{~h}$ onwards. Direct comparison of the locomotion evaluations is difficult because different scales were used.

Hoof-Testing. Reaction to hoof-testing is perceived to be dependent not only on foot pain but also on the consistency, moisture, and thickness of the horn (Ross,
2003); the pressure applied and technique used by the person operating the hoof-tester; and the willingness of the animal to cooperate (Stashak, 2002). Consequently, standardizing the conditions for hoof-testing is difficult. Dyer et al. (2007) presented a method to standardize and record the pressure applied by the hoof-tester, and this may improve the usefulness of the test considerably. Still, the interpretation of the reaction remains subjective.

In the present study, claw trimming was performed before the trial, heifers were trained, and measures were taken to standardize pressure, technique, and interpretation. Nonetheless, although the clinical information obtained was regarded as useful, hoof-testing as a scientific test should be interpreted with caution. Thoefner et al. (2004) observed positive reaction to hoof-testing in the same claw on 2 consecutive examinations in 5 of 6 heifers between 33 and $48 \mathrm{~h}$. In the present study, this was only seen in 1 of 7 heifers over the same time period. These differences may be due to different environmental conditions. In the study undertaken by Thoefner et al. (2004), the heifers were loose-housed with a small outdoor paddock. It is possible that the additional moisture softened the horn and that exercise predisposed the heifers to earlier development of a positive reaction to hoof-testing and lameness.

Evaluation of Tarso-Crural Joints. The relatively short period of moderate to severe joint distension implies that the acute joint reaction was transitory, but the clinical consequence is not yet clear. Also, a diffuse swelling over the coronary bands was observed in some heifers. Even though distinct swelling of other synovial structures was not observed, the reaction may not be limited to the tarso-crural joints but be of a more generalized nature. Aseptic arthritis and tenosynovitis were described in cattle with generalized disease (Stockfleth, 1870; Dirksen, 2002), and arthritis was observed in cattle suffering from laminitis with concurrent general affection (Andersson and Liberg, 1980). Horses with oligofructose-induced laminitis developed joint and tendon sheath effusion (C. Pollitt, University of Queensland, Brisbane, Australia, personal communication) as well as distal limb edema (van Eps and Pollitt, 2006). In clinical practice, indistinct swelling of the limbs is often observed in connection with changes in feeding regimen, for instance after calving (Greenough et al., 2007).

\section{General Clinical Examination}

By and large, the developments in general clinical signs and laboratory variables observed in this study supported the findings of Thoefner et al. (2004). Nevertheless, in the present study, the heaviest heifers, 
which were generally the fattest, seemed more severely affected by the oligofructose overload than lighter, thinner heifers. The administered dose of oligofructose was calculated per kilogram of BW. Fat cows had smaller rumen capacity per kilogram of BW than thin cows of similar body size (Nutt et al., 1980). Consequently, it was possible that the fat heifers received a relatively larger amount of oligofructose per liter of rumen volume than the thin heifers. In the study by Thoefner et al. (2004), the heifers receiving the greatest dose oligofructose tended to develop greater heart rates and needed more supportive fluid therapy than those receiving lower doses. In light of these observations, a dosage calculation that takes into consideration the capacity of the forestomach might be advisable in future use of the oligofructose model.

Animal Excluded from the Study. The most severely affected heifer had to be withdrawn from the experiment and subsequently died. Several factors may have had an effect on the course of the disease. This heifer was in very good condition, originated from a different herd, and had less time to adapt to the feeding than the other heifers. Additionally, the heifer had been fed differently (on pasture) before the acclimatizing period. This may indicate that adaptation to new feed is slow and that an acclimatizing period of $17 \mathrm{~d}$ was insufficient to standardize the ruminal flora. Experience with oligofructose overload indicated that previous feeding and acclimatizing was vital to the outcome and usefulness of the model. In 4 heifers fed with whole grain silage before oligofructose overload, only mild systemic reaction and minimal lameness was observed (A. M. Danscher, unpublished data). A group of fattening calves ( $82 \mathrm{~kg}$ of BW, range 63 to $100 \mathrm{~kg}$ ) fed intensively until $9 \mathrm{~d}$ before oligofructose overload developed diarrhea but showed minimal systemic signs and no orthopedic reaction (J. Wenz, Washington State University, Pullman, personal communication). Horses taken directly from pasture and dosed with oligofructose developed severe hemoconcentration and hypovolemia and had to be euthanized $24 \mathrm{~h}$ after overload (van Eps and Pollitt, 2006).

It will be important to ensure that these experiences are taken into account if the model is used in the future. Equally, diligent surveillance of the animals and strictly defined humane endpoints are needed to secure the greatest possible levels of experimental animal welfare.

\section{CONCLUSIONS}

The present study showed that oligofructose overload in dairy heifers induced lameness, claw pain, and joint effusion as well as concurrent systemic signs, collectively interpreted as signs of acute laminitis. The lameness was mild to moderate and improved relatively quickly. The locomotion scores were greatest on $\mathrm{d} 3$ to 5 after overload. Reaction to hoof-testing was observed primarily on d 4 to 9 and joint distension on d 2 and 3.

Oligofructose overload at the dose used represented a relatively mild model of acute laminitis in cattle. Nevertheless, the systemic effect resulting from the ruminal acidosis can be very severe and is apparently influenced by body condition and the previous feeding regimen. The model can be used to investigate the pathogenesis of acute bovine laminitis, but use of the model should be combined with rigorous surveillance procedures.

\section{ACKNOWLEDGMENTS}

This study was a part of the "Sund Klov" (Healthy Claw) project supported by the Danish Milk Levy Fund. Additional financial support was granted from Fors $\varnothing$ gsleder R. Nørtoft Thomsens Legat and Vetfond. We thank Niels Bastian Kristensen, Faculty of Agricultural Sciences, University of Aarhus (Denmark), for analyzing ruminal samples and providing the equipment for blood gas analysis and Nicolai Agger, Pharmalett (Kolding, Denmark), for providing equipment for ruminal intubation. We wish to thank Pia H. F. Andersen (University of Copenhagen, Denmark) in particular for her help and constructive comments during the preparation of the manuscript.

\section{REFERENCES}

Agresti, A. 2002. Pages 275-277 and 435. Categorical Data Analysis. 2nd ed. John Wiley and Sons, Hoboken, NJ.

Andersson, L., and P. Liberg. 1980. Blood serum and synovial fluid in bovine laminitis and arthritis, with particular reference to the protein composition. Acta Vet. Scand. 21:567-577.

Bailey, S. R., C. M. Marr, and J. Elliott. 2004. Current research and theories on the pathogenesis of acute laminitis in the horse. Vet. J. 167:129-142.

Brenninkmeyer, C., S. Dippel, S. March, J. Brinkmann, C. Winckler, and U. Knierim. 2007. Reliability of a subjective lameness scoring system for dairy cows. Anim. Welf. 16:127-129.

Dirksen, G. 2002. Krankheiten der Bewegungsorgane. Pages 753-1029 in Innere Medizin und Chirugie des Rindes. G. Dirksen, H.-D. Gründer, and M. Stöber, ed. Parey Buchverlag, Berlin, Germany.

Dyer, R. M., N. K. Neerchal, U. Tasch, Y. Wu, P. Dyer, and P. G. Rajkondawar. 2007. Objective determination of claw pain and its relationship to limb locomotion score in dairy cattle. J. Dairy Sci. 90:4592-4602.

Ersboel, A. K., J. Bruun, and N. Toft. 2004. Data analysis. Page 256 in Introduction to Veterinary Epidemiology. H. Houe, A. K. Ersboel, and N. Toft, ed. Biofolia, Frederiksberg, Denmark.

Greenough, P. R., C. Bergsten, A. Brizzi, and C.-K. W. Mulling. 2007. The Laminitis Syndrome. Pages $36-54$ in Bovine Laminitis and Lameness - A Hands on Approach. 1st ed. Saunders Elsevier, Philadelphia, PA.

March, S., J. Brinkmann, and C. Winkler. 2007. Effect of training on the inter-observer reliability of lameness scoring in dairy cattle. Anim. Welf. 16:131-133. 
Nilsson, S. A. 1963. Clinical, morphological, and experimental studies of laminitis in cattle. Acta Vet. Scand. 4(Suppl. 1):7-304.

Nutt, B. G., J. W. Holloway, and W. T. Butts. 1980. Relationship of rumen capacity of mature Angus cows to body measurements, animal performance and forage consumption on pasture. J. Anim. Sci. 51:1168-1176.

O'Callaghan, K. A., P. J. Cripps, D. Y. Downham, and R. D. Murray. 2003. Subjective and objective assessment of pain and discomfort due to lameness in dairy cattle. Anim. Welf. 12:605-610.

Ossent, P., P. R. Greenough, and J. J. Vermunt. 1997. Laminitis. Pages 277-292 in Lameness in Cattle. P. R. Greenough and A. D. Weaver, ed. W. B. Saunders, Philadelphia, PA.

Pavis, N., N. J. Chatterton, P. A. Harrison, S. Baumgartner, W Praznik, J. Boucaud, and M. P. Prud'homme. 2001. Structure of fructans in roots and leaf tissues of Lolium perenne. New Phytol. 150:83-95.

Ross, M. W. 2003. Palpation. Pages 42-60 in Diagnosis and Management of Lameness in the Horse. M. W. Ross and S. J. Dyson, ed. Saunders, St. Louis, MO.
Sprecher, D. J., D. E. Hostetler, and J. B. Kaneene. 1997. A lameness scoring system that uses posture and gait to predict dairy cattle reproductive performance. Theriogenology 47:1179-1187.

Stashak, T. S. 2002. Examination for lameness. Pages 113-183 in Adams' Lameness in Horses. T. S. Stashak, ed. Lippincott, Williams and Wilkins, Baltimore, MD.

Stockfleth, H. V. 1870. Sygdomme i synovialhinderne (Diseases in the synovial membranes) Pages 201-202 in Haandbog i Veterinærchirugien, Første Deel (Handbook of Veterinary Surgery, Part 1). Forlaget af den Gyldendalske Boghandel, Copenhagen, Denmark.

Thoefner, M. B., C. C. Pollitt, A. W. van Eps, G. J. Milinovich, D. J. Trott, O. Wattle, and P. H. Andersen. 2004. Acute bovine laminitis: A new induction model using alimentary oligofructose overload. J. Dairy Sci. 87:2932-2940.

Thoefner, M. B., O. Wattle, C. C. Pollitt, K. R. French, and S. S. Nielsen. 2005. Histopathology of oligofructose-induced acute laminitis in heifers. J. Dairy Sci. 88:2774-2782.

van Eps, A.-W., and C. C. Pollitt. 2006. Equine laminitis induced with oligofructose. Equine Vet. J. 38:203-208. 